\title{
Afrontamiento Religioso y Política: Las Lecciones de la Respuesta al SIDA
}

\author{
Vera Silvia Facciolla Paiva ${ }^{1}$ \\ Departamento de Psicologia Social e do Trabalho da Universidade de São Paulo, \\ São Paulo, Brasil \\ Andrea Paula Ferrara \\ Mafoane Odara Poli Santos \\ NEPAIDS - Instituto de Psicologia da Universidade de São Paulo, São Paulo, Brazil \\ Richard Parker \\ Department of Sociomedical Sciences of Columbia University, New York, USA
}

\section{Resumen}

Afrontamiento con la enfermedad y las interacciones entre diversas formas de religiosidad son desafíos para la práctica de los profesionales de la salud, sobre todo cuando se trata de la sexualidad. ¿Qué lecciones ofrece el afrontamiento con el SIDA? Basado en estudio documental, estudios de casos, talleres y entrevistas, este artículo discute la respuesta al SIDA a través de la perspectiva de los líderes religiosos que vivieron sus primeras décadas en São Paulo, Brasil. Las nociones de solidaridad, los derechos humanos y ecumenismo se articularon en la construcción de la respuesta social a la epidemia, incluyendo los esfuerzos de prevención centradas en el uso del condón. Estas ideas expresan el período histórico en el que la movilización de la democracia post-dictadura apareció paralelamente a la crisis del SIDA. Tal como en otras instituciones religiosas, "católico-humanistas", dentro y fuera del gobierno y de la jerarquía de la Iglesia, han producido un "estilo colaborativo" de afrontamiento religioso. En el campo católico, personas enfermas de SIDA, inclusive padres y seminaristas, fueron amparados con apoyo de la Arquidiócesis, mientras un intenso debate interno oponía a "pastorialistas" y adeptos a la teología de la liberación, a los "canonistas" y seguidores del Vaticano, especialmente en la prevención campo donde los "vaticanistas" diseminaban un discurso de afrontamiento moralista de estilo "delegante". Religiosos en cualquier posición - fieles, clérigos, autoridades -producen o reproducen discursos con estilos de afrontamiento religioso a la enfermedad disponibles en sus contextos socio-culturales e políticos; sus simbolismos permanecen implicados en el enfrentamiento personal - con repercusiones cognitivas, emocionales y de comportamiento. Estudios y prácticas profesionales en el campo del afrontamiento religioso se enriquecerían al considerar dimensiones que no pueden reducirse al comportamiento individual y a la relación con el dogma, lo sagrado y lo transcendental. Una comprensión más amplia de las dimensiones psicosociales, institucionales, y políticas, también la interacción con la religiosidad viva, enriquecerá la investigación y la práctica profesional.

Palabras clave: Afrontamiento, religión, SIDA, instituciones.

\footnotetext{
Endereço para correspondência: Departamento de Psicologia Social e do Trabalho, Instituto de Psicologia, Universidade de São Paulo, Av. Prof. Mello Moares, 1721, Cidade Universitária, São Paulo, SP, Brasil 05508900. E-mail: veroca@usp.br, apferrara@uol.com.br,mafoane@gmail.comergp11@columbia.edu Agências de Financiamento: National Institutes of Health (NIH) /USA, Mac Arthur Foundation e Conselho Nacional de Desenvolvimento Cientifico e Tecnológico (CNPq).
} 


\title{
Enfrentamento Religioso e Política: As Lições da Resposta à Aids
}

\section{Resumo}

O enfrentamento do adoecimento e a interação com diferentes religiosidades são desafios para a prática profissional, especialmente quando a sexualidade está envolvida. Que lições o enfrentamento religioso da Aids poderia oferecer? Baseado em pesquisa documental, estudos de caso, oficinas e entrevistas, este artigo discute o enfrentamento da Aids nas primeiras décadas de epidemia em São Paulo na perspectiva de religiosos. Lideranças de várias tradições religiosas co-construíram a resposta social à epidemia, incluindo a prevenção centrada no uso do preservativo. Noções de solidariedade, direitos humanos e ecumenismo expressavam a mobilização democrática pós-ditadura paralela à emergência da doença. "Católico-humanistas" no governo compartilhavam essa perspectiva com seus pares da hierarquia católica, estimulando um enfrentamento religioso de estilo "colaborativo". Doentes com Aids, inclusive padres e seminaristas, foram acolhidos com apoio da Arquidiocese, enquanto acirrado debate interno opunha pastoralistas e adeptos da teologia da libertação aos canonistas (vaticanistas) que, desde então, disseminaram um discurso de enfrentamento de "estilo delegante" e moralista, especialmente no campo da prevenção. Religiosos em qualquer posição (fiéis, clérigos, autoridades) produzem e reproduzem discursos implicados em estilos de enfrentamento religiosos disponíveis em seus contextos socioculturais e políticos; seus simbolismos permanecem no enfrentamento pessoal - com efeitos cognitivo-emocionais e comportamentais. $\mathrm{O}$ enfrentamento religioso não pode ser reduzido ao comportamento individual e à relação pessoal com o dogma, o sagrado e o transcendental. Uma compreensão mais ampla das suas dimensões psicossociais e político-institucionais, assim como a interação do discurso técnico com a religiosidade viva, enriquecerão a pesquisa e a prática profissional na promoção da saúde.

Palavras-chave: Enfrentamento, religião, aids, instituições.

\section{Religious Coping and Politics: Lessons from the Response to Aids}

\begin{abstract}
Religious coping with illness and the interactions among diverse forms of religiosity have posed challenges for the practice of health professionals, especially when sexuality is involved. What lessons can coping with AIDS offer? Based on archival research, case studies, workshops, and interviews, this article discusses the response to AIDS through the perspective of religious leaders who lived through its first decades in São Paulo, Brazil. Notions of solidarity, human rights, and ecumenicalism were articulated in the construction of the social response to the epidemic, including prevention efforts centered on condom use. These ideas expressed the historical period when mobilization for democracy post-dictatorship paralleled the AIDS crisis emergence. As in other religious traditions, "humanist-Catholics" in the government shared this perspective with their peers in the higher rungs of the Church, producing a "collaborative" religious coping style. In the Catholic responses, people with AIDS, including priests and seminarians, were cared for with the support from the Archdiocese, while the strained internal debate created opposition among "pastoralists" and followers of Liberation Theology and "canonists", especially in the field of prevention in which the Vatican delivered a discourse of a moral and "delegating" style of coping. Religious followers in whatever position - followers, clergy, authorities - produce and reproduce discourses on religious coping available in their socio-cultural and political contexts; its symbolisms remain implicated in personal coping - with cognitive, emotional and behavioral effects. Religious coping cannot be reduced to individual behavior and its relationship with dogma, the sacred and the transcendental. A broader comprehension of its psychosocial and institutional-political dimensions, as well as the interaction with the lived religiosity will enhance the research and the professional practice.
\end{abstract}

Keywords: Coping, religion, aids, institutions. 
El aumento en las oportunidades de empleo en el campo de la salud y la asistencia social amplió el horizonte para el trabajo del psicólogo. ${ }^{2}$ Recientemente, nuevas prácticas se desarrollaron en el ámbito de la atención médica básica y en contextos de hospitales altamente complejos, y modelos psicoterapéuticos y de prevención se han actualizado (Centro de Referência Técnica em Psicologia e Políticas Públicas [CREPOP], 2008, 2009; Perucchi, Rodrigues, Jardim, \& Calais, 2011; Sampaio \& Araújo, 2006; Zurba, 2011). Uno de los desafíos para el desempeño profesional en este contexto es la interacción de la religiosidad de los pacientes con la de los profesionales de la salud.

En la literatura académica sobre la religión y la psicología, dos tipos de preguntas son las más comunes: cómo se considera o se lida con la religiosidad de los pacientes en el ámbito de las prácticas psicoterapéuticas, y cuál es el papel del comportamiento religioso como un factor para afrontar con los contextos sociales de la enfermedad (Faria \& Siedl, 2005; Peres, Simão, \& Noasello, 2007). La religiosidad de los profesionales de la salud y de las autoridades religiosas es todavía raramente explorada en investigaciones, a pesar de la incomodidad de las personas con creencias religiosas firmes al encontrar teorías psicológicas. ${ }^{3} \mathrm{La}$ comprensión de la dinámica religiosa de los que producen los discursos sociales y políticos que le dan significado contextual al afrontamiento religioso como un fenómeno psicológico incorporado es un vacío importante en el debate académico (Garcia, Muñoz-Laboy, Almeida, \& Parker, 2009).

En los consejos que vigilan y regulan la práctica profesional, por otro lado, la reflexión

En el Brasil esto se desarrolla en el Sistema Único de Saúde (SUS) y el en Sistema Único de Asistencia Social (SUAS) establecidos desde 1988 y 2005, respectivamente, como sistemas públicos que organizan, de forma descentralizada, los servicios de atención, vigilancia, salud preventiva (SUS) y asistencia social (SUAS).

3 La religiosidad de los psicólogos y la de sus pacientes se describe como una de las motivaciones de los estudiantes para abordar el tema de la interacción de la psicología y la religión (G. J. Paiva et al., 2009). crítica y conceptual sobre la religiosidad de los psicólogos floreció en paralelo con el surgimiento de la epidemia del SIDA y de los movimientos sociales que socioculturalmente y políticamente afirmaron la identidad homosexual. La literatura académica indica que la condenación religiosa de la homosexualidad contribuye a la producción de la estigmatización y la discriminación de los homosexuales, que, a su vez, han sido asociados con las principales vulnerabilidades a los problemas de salud mental y sexual en culturas diversas (Garrido, Paiva, Nascimento, Souza, \& Santos, 2007; Gough, 2007; Govender, 2011; Kian \& Anderson, 2009; Parker \& Aggleton, 2001, 2003). En Brasil, la resolución del Consejo Federal de Psicología (Resolución $\mathrm{CFPN}^{\circ}$ 01/99) expresó el debate alrededor de estas conclusiones utilizando un marco basado en los derechos humanos, que ha sido invocado con frecuencia en respuesta al SIDA y ha aconsejado contra las prácticas terapéuticas con el objetivo de curar la homosexualidad o que contribuyan a la discriminación de los no-heterosexuales.

El campo de la prevención de VIH/SIDA y del cuidado a personas enfermas tiene lecciones que ofrecer. La eficacia en este campo ha dependido de la innovación técnica para trabajar con la interacción entre las diferentes formas de religiosidad, lo que exige el respeto a los diversos estilos de vida de los clientes de servicios de salud y desafió prácticas profesionales fuertemente marcadas por los valores personales. En la promoción de los condones, en el cuidado de los enfermos, en la atención primaria o en el ámbito de la asistencia social, las respuestas de los profesionales de la saluda la epidemia estimularon la revisión de las teorías y técnicas utilizadas en los estudios universitarios, especialmente en el campo de la sexualidad (Parker, Garcia, \& Muñoz-Laboy, 2013). Estas respuestas también validaron la perspectiva de derechos humanos en las profesiones relacionadas con la salud (Gruskin \& Tarantolla, 2008, 2012; V. Paiva, 2008).

Estos desafíos no se limitan al contexto brasileño. Hablar de un panorama mundial de la epidemia en su segunda década, Mann y Tarantola (1996) incluyen la religión como un factor importante a considerar cuando se habla de la 
vulnerabilidad social. Ellos entendieron que para una gran parte del mundo la religión da significado a la vida, al nacimiento, al matrimonio, al sufrimiento ya la muerte. Los líderes religiosos crean normas que regulan la sexualidad, se involucran en la política y en la legislación, así como en los programas educativos, en las instituciones médicas, y tienen influencia sobre la cultura de la salud y la enfermedad. Los autores cuestionaron si los profesionales de la salud deberían temer las intervenciones religiosas, o si ellos "deberían considerar los líderes religiosos y morales como aliados en el contexto del SIDA?" (Mann \& Tarantola, 1996, p. 447). Como discutió Defert (1996), los programas en varios países abordaron la sexualidad, el estigma y el uso del condón de manera secular y no han encontrado una respuesta sencilla a esta pregunta.

Si tomamos el período de la emergencia del $\mathrm{VIH} /$ SIDA como un ejemplo, podemos observar diferentes manifestaciones públicas que muestran cómo las instituciones religiosas se han enfrentado a la crisis de la epidemia desde 1980. Líderes e instituciones religiosas se han hecho conocidos alrededor del mundo por sus esfuerzos para movilizarla solidaridad y la atención a las personas afectadas por la epidemia (Garcia \& Parker, 2011; Sanchez \& Nappo, 2008). Por otra parte, mientras que algunos líderes religiosos, familiares y funcionarios de diversas áreas de la salud respondieron a la necesidad de controlarla pandemia y mitigar el sufrimiento físico y mental de los enfermos, muchos líderes políticos y profesionales de la salud exacerbaron el estigma y la discriminación asociados con el VIH basada en su fe personal- desde púlpitos de las iglesias, trabajando en servicios de salud pública, e incluso en las universidades (Farmer, 1999; Galvão, 1997; Garcia et al., 2009; V. Paiva \& Zucchi, 2012).

En Brasil, la epidemia del SIDA y el movimiento de democratización surgieron durante el mismo período histórico (Berkman, Garcia, Munoz-Laboy, Paiva, \& Parker, 2005). En 1988, la Constitución brasileña garantizo las acciones gubernamental es que aseguraban la libertad religiosa y la secularidad del Estado, así como el derecho al acceso universal a la atención integral de salud que incluya la prevención y la rehabilitación. Durante las próximas dos décadas, la política gubernamental y los programas de prevención centrados en el uso del condón fueron ampliamente aceptados, a pesar de que una gran mayoría de los brasileños se declaran católicos y el Vaticano ha estado en contra del uso del condón ${ }^{4}$ (V. Paiva, Aranha, Bastos, \& Grupo de Estudos em População, Sexualidade e Aids [GEPSAIDS], 2008). ¿Cómo debemos interpretar este contexto social, cultural y político y a que afecta los resultados psicológicos?

Los científicos sociales que trabajan sobre la religión en Brasil destacan que las dimensiones personales y cotidianas deben ser considerados en la documentación de la historia de la religión (Burdick, 1996; Chesnut, 1997). Describen cómo la dinámica de la religión, la ética privada, y la agencia individual del sujeto religioso son desafiadas con frecuencia por la vida cotidiana (Duarte, 2005; Watanabe, 2005). Estas dinámicas han producido polarización en reacción a la epidemia y son una parte integral de la "respuesta brasileña al SIDA".

\section{Afrontamiento Religioso}

En el campo de la psicología de la religión en Brasil, G. J. Paiva (1998, p. 28) trae a nuestra atención la literatura sobre el estrés y afrontamiento en el contexto de la relación entre la salud, la religión y el VIH/ SIDA, especialmente expandiendo el trabajo de Pargament ${ }^{5}$ quien definió el afrontamiento como un proceso de lidiar con importantes exigencias personales y situa-

4 Un estudio nacional de hogares observó que la educación sobre el uso de condones en las escuelas para los estudiantes mayores de 15 años fue fuertemente apoyada por aquellos de todas las afiliaciones religiosas-en un $94.5 \%$ de los pentecostales, el $98.5 \%$ de los católicos, y el 100\% de los miembros de las religiones afro-brasileñas. Este estudio también mostró que el $83 \%$ apoyó la disponibilidad de condones para los adolescentes en las escuelas y el $94 \%$ apoyó su disponibilidad en los puestos de salud (V. Paiva et al., 2008).

5 Pargament, K. I. (1990). God help me: Toward a theoretical framework of coping for the psychology of religion. Research in the Social Scientific Study of Religion, 2, 195-224. 
cionales, un fenómeno psicosocial que el surgimiento del SIDA movilizó.

Los investigadores de estrés y afrontamiento fueron los primeros en el campo de la psicología para enfocarse en las personas afectadas por el SIDA, antes de la existencia de los antirretrovirales (Coates, Temoshok, \& Mandel, 1984; Vasconcellos, 1992). Entre los aspectos más importantes de la evaluación de situaciones que requieren afrontamiento es el proceso de atribuir un origen (causa) al evento estresante y la identificación de las reacciones a este evento. La literatura sobre el afrontamiento religioso en situaciones de estrés-principalmente como resultado principalmente de los estudios sobre los cristianos-describe cuán determinantes pueden ser causas de los acontecimientos, especialmente los negativos, son atribuidos a Dios, y cómo la gente permanece pasiva y Dios es visto como un agente activo.

Bastante sofisticada, la teoría de afrontar el estrés se dedica fundamentalmente al estudio del contexto de una enfermedad crónica, como el VIH y el SIDA que a menudo se enmarcan como enfermedades crónicas hoy en día en los lugares donde los antirretrovirales están disponibles. El proceso de afrontamiento descrito en la literatura incluye repercusiones sobre los niveles cognitivos, emocionales y de comportamiento. Los estudiosos que utilizan este marco teórico se posiciona fuertemente en la psicología social: teniendo una comprensión que afrontamiento es influenciado por la cultura, el modelo de las evaluaciones de situación, y postulando que el "sistema de orientación de las personasen el mundo y sus estrategias de afrontamiento" se pueden "enseñar y ser privilegiadas en un contexto sociocultural en perjuicio de los demás" (Faria \& Seidl, 2005, p. 383). Las funciones de la religión en el afrontamiento y la resolución de problemas dependerá del estilo de afrontamiento adoptadas por la persona, de cómo se atribuyó la responsabilidad, y de la medida en quela persona participa voluntariamente. En el estilo de auto-dirigida del afrontamiento religioso en eventos estresantes, la responsabilidad de afrontar problemas se coloca en el individuo autónomo, sin referencia trascendental. En el estilo de delegante, la solu- ción se deja a la esfera divina, frecuentemente "en las manos de Dios". El estilo de colaborativo se basa en la participación y la responsabilidad del individuo y de lo divino (Faria \& Siedl, 2005; G. J. Paiva, 1998).

Este artículo tratará el afrontamiento religioso desde la perspectiva de los líderes religiosos que participaron en los primeros años de la construcción de una respuesta social y psicológica al SIDA en São Paulo y en varias posiciones institucionales, centrándose especialmente en los católicos. Describimos las formas en que expresan su religiosidad en el advenimiento de la epidemia, mientras interactuaban con una respuesta gubernamental al SIDA, que estaba basada en la evidencia producida en el ámbito de la epidemiología, infectología, medicina preventiva, entre otras disciplinas.

\section{Método}

Los datos analizados en este estudio fueron colectado en el ámbito del una investigación multi-sitio cuyo ${ }^{6}$, objetivo más general era comprender cómo instituciones de tradiciones religiosas cristianas y afro-brasileñas concebían el SIDA y de qué manera se articularon para participar en la respuesta social y política al SIDA.

La metodología utilizada para la discusión que se sigue fue planeado con base en el modelo de Burawoy (2009) conocido como "extended case method", donde se combinan la observación directa y el análisis histórico basado en la observación sobre diversos momentos a lo largo del tiempo. Este tipo de análisis permite comprender cómo fuerzas políticas y estructurales se relacionan. Un análisis preliminar de docu-

6 Este artículo se basa en los datos recogidos en el estudio "Las respuestas religiosas al VIH/ SIDA en Brasil". El estudio nacional fue coordinado desde 2005 hasta 2009 por Richard G. Parker y se llevó a cabo en cuatro ciudades: Río de Janeiro (coordinado por Veriano Terto Jr.), Porto Alegre (coordinado por Fernando Seffner), Recife (coordinado por Felipe Ríos) y São Paulo (coordinado por Vera Paiva). Información adicional sobre este proyecto se puede obtener en http.abiaids.org.br, la página web de la Asociación Brasileña Interdisciplinar de SIDA. 
mentos (por ejemplo, medios, de informes de gobierno, de las organizaciones estudiadas, y de la literatura académica) fue fundamental para la selección de informantes-claves en el proceso de investigación.

En el caso analizado aquí - las respuestas religiosas al SIDA en São Paulo en las dos primeras décadas de la epidemia-la primera actividad de investigación fue una entrevista de grupo organizado como un taller de debate entre los líderes religiosos de las tres tradiciones religiosas focalizadas -Católica, Umbanda-Candomblé, Protestantes-evangélicos- junto con profesionales de la salud de los programas de SIDA que participaron en varios momentos de la respuesta religiosa- incluyendo psicólogos, médicos y trabajadores sociales. Una "línea de tiempo", producido colectivamente fue el principal resultado de los testimonios personales sobre cómo cada narrador afronto la crisis del SIDA y debates sobre esta historia social de la epidemia en São Paulo. ${ }^{7}$ En la parte inicial del taller, los grupos fueron separados de acuerdo con la tradición religiosa, y más tarde en el día nos reunimos en un ambiente de grupo inter-religioso para construir una única narrativa y reflexionar críticamente sobre ello.

El análisis en este artículo también se basa en el relato de 78 entrevistas en profundidad, realizadas entre 2005 y 2008. Todos los entrevistados-sacerdotes y sacerdotisas de religiones afro-brasileñas, pastores, sacerdotes, capellanes, miembros de organizaciones sociales religiosas, activistas de la Pastoral de ETS/SIDA ${ }^{8}$, catequistas, y profesionales de la salud-de los programas de SIDA participaron directamente en la res-

El resultado de esta actividad se publica en Souza, Santos, Almeida y Paiva (2012) y esta disponible en versiones traducidas en Inglés y Español.

8 La variedad de "pastorales" que llevan a cabo el trabajo social burocráticamente estructurado de la Iglesia Católica en Brasil ofrece respuestas particulares a los problemas sociales relacionados con la familia, jóvenes, niños, mujeres marginadas (un eufemismo utilizado para describir las profesionales del sexo), negros, entre otros. Existe una Pastoral específica dedicada al SIDA, que se encuentra en Porto Alegre (véase, por ejemplo, Seffner et al., 2008). puesta del gobierno y no-gubernamental durante los primeros años de la epidemia, en São Paulo.

Para este análisis, nos acercamos de manera significativa a partir de datos recolectados como un estudio de caso de una organización no-gubernamental (ONG) fundada en la década de 1980, donde se realizaron estudio documental y entrevistas con los coordinadores, empleados y clientes.

Los líderes históricos entrevistados, algunos de edad avanzada, también nos dieron documentos históricos primarios que se utilizaron en este análisis. Entre los documentos examinados para este texto, resaltamos las actas del Grupo de Trabajo SIDA y Religiones junto con el Programa Estadual de ETS/SIDA del Estado de São Paulo y documentos accedidos en estudio conducido en los Archivos de la Curia Metropolitana y Biblioteca de la CNBB (Confederación Nacional de los Obispos) en São Paulo.

Todos los entrevistados y participantes de actividades en grupo firmaron un término de consentimiento, libre y aclarado antes de las recogida de datos a través de grabaciones de audio que fueron transcritas. El proyecto fue aprobado por la Comisión Nacional de Ética en Estudio (CONEP) del Ministerio de Salud Brasileño.

El marco para este análisis es un aborde social sobre la salud de una perspectiva construccionista y basado en los derechos humanos (V. Paiva, 2012a, 2012b). Utilizado y globalizado en el contexto de la respuesta mundial al SIDA (Gruskin \& Tarantola, 2008, 2012) la perspectiva basada en los derechos humanos y de la vulnerabilidad (individual, social y programática) para entender la salud y la enfermedad enfatiza una "historia social de la enfermedad" y no que una "historia natural de la enfermedad." Esto no sólo es importante porque es imposible pensar en los procesos de salud y enfermedad como independientes de los determinantes culturales, históricas, y estructurales, sino también porque la perspectiva social ofrece una forma de transmitir esta historia (Ayres, Paiva, \& França, 2010, 2012).

En revisitar la historia social del SIDA basada en los relatos de los líderes religiosos analizados desde esta óptica conceptual, este texto se propone ampliar nuestra comprensión de afron- 
tamiento religioso, que no se discutirá exclusivamente desde un punto de vista individualista y de comportamiento.

\section{El Contexto de la Respuesta a los Primeros Casos de SIDA en São Paulo}

Todos los años ellos preparan una liturgia para rezar por las víctimas del SIDA. ¿De quésirve? Ellos ya están con Dios, no necesitan más de tu oración... En el comienzo, nosotros teníamos en São Paulo a Don Paulo y él era a favor del preservativo, con la teoría de que "entre los males, era el menor". Apoyado por muchos religiosos, muchos obispos, padres. Yo, personalmente, siempre decía: si es para prevenir, preservar la vida, entonces no es un mal mayor, sino un bien mayor. Debemos siempre verla defensa de la vida y hacer de todo para defenderla, usar todos los medios que nuestra inteligencia alcanza para poder hacer que nuestra vida sea vivida con plenitud. Este es el pensamiento de Cristo, el pensamiento del evangelio. "Yovine para que todos tengan vida y tengan plenitud". (Padre, entrevistado en 2006)

Varios factores contribuyeron a que el estado de São Paulo respondiese rápidamente a la epidemia y organizase el primer programa de SIDA de las Américas en 1983. La ciudad de São Paulo, más allá de centro de negocios y polo industrial del país, era sede de una sinergia de movimientos sociales de resistencia a la dictadura desde los años 1970: movimientos estudiantiles por libertades democráticas, movimientos sindicales por la dignidad en el trabajo ${ }^{9}$, además del movimiento homosexual y de los movimientos de mujeres contra la pobreza en coalición con el movimiento feminista.

Contemporánea al registro de los primeros casos de SIDA, la llamada "política de distensión" del gobierno militar permitió, después de dos décadas de dictadura, la elección por voto

Liderados por Lula da Silva - que fue presidente de Brasil entre 2002-2010. popular de gobiernos locales. El gobernador electo en 1982, Franco Montoro, profesor de filosofía y originario del movimiento "humanista cristiano", contrastaba con otros gobernantes católicos y conservadores indicados por décadas por los militares en toda América Latina. Los humanistas defendían la "dignidad de la persona humana" en diversos movimientos sociales. Al tomar puestos como los funcionarios del gobierno, hacían frecuentes referencias a la Declaración Universal de los Derechos Humanos de 1948, a la "ética de la solidaridad", al principio de la "participación" y a la promoción de la ciudadanía "que no es apenas derecho, sino una toma de consciencia y responsabilidad social" (Pollozi \& Souza, 2001, p. 13).

El gobierno estatal acogió una respuesta casi inmediata a los primeros casos de SIDA en 1981-1982, y los profesionales de la salud que encabezaban esta respuesta habían participado en el movimiento de reforma sanitaria desde la década de 1970 y en este momento actuaron como servidores públicos de la Secretaría de Salud del Estado y en los municipios más afectados, defendiendo el derecho universal a la salud.

Por lo menos un año antes de la articulación del Programa Nacional de SIDA, este escenario político produjo la primera organización no-gubernamental (ONG) brasileña dedicada a las personas afectadas por el SIDA (Grupo de Apoyo a la Prevención del SIDA [GAPA]), que también fue organizada por profesionales de la Secretaría Estadual de la Salud y por líderes del movimiento homosexual y de derechos humanos.

Los testimonios de informantes claves que participaron de ese momento, indicaron que, desde luego, muchos religiosos buscaban informaciones reaccionando a los casos de SIDA en sus iglesias, en sus terreiros (templos de religiones afro-brasileñas), y en sus centros espíritas. Esos lideres religiosos optaron por la no exclusión de los portadores de VIH en su comunidad religiosa y buscaban profesionales de salud con el objetivo de estar informados por el discurso técnico-científico. En buena parte de esos líderes religiosos había una historia anterior de actuación en trabajos sobre problemas sociales: eran católicos provenientes del Movimiento de las 
Comunidades Eclesiales de Base ${ }^{10}$ por justicia social y salud, protestantes vinculados al Movimiento Ecuménico y a la lucha por los Derechos Humanos, adeptos de religiones afro-brasileñas que luchaban contra la intolerancia religiosa y a favor de la cultura de la paz. Documentos de la época mencionan explícitamente la promoción de los derechos económicos y sociales de los más pobres, la defensa de la democracia y el compromiso de movilizar organizaciones sociales con voz para luchar por sus intereses.

En 1985, con apoyo del Programa Estadual de ETS/SIDA de São Paulo, los religiosos de matrices afro-brasileñas, produjeron un manual de cómo manipular navajas y tijeras de forma segura, buscando la continuación de sus rituales, siendo acusados de diseminar "cosas malas... de esta vez, de esparcir el virus del SIDA". En 1986, se organizó el Grupo Especial de Cultura, Candomblé y SIDA (GECAIDS) cuando ya se contaban decenas de sacerdotes de esta tradición religiosa entre los enfermos que morían de SIDA.

10 La Iglesia Católica de Brasil "jugó un papel fundamental en la articulación de la sociedad civil, en defensa de los derechos humanos, de las libertades democráticas, la reforma agraria, los derechos de los trabajadores y de la redemocratización" (Azevedo, 2004, p. 112). La relación entre la Iglesia Católica Romana en la cultura política brasileña hace que esta institución y sus iniciativas particularmente importante en el estudio de la acción política contra la dictadura. Los movimientos sociales de base relacionados con la Iglesia se llevaron a cabo principalmente en Comunidades Eclesiales de Base (CEBs), que proporcionaron espacios para la movilización y la formación de redes. Estos espacios y la participación de los líderes de la elite católica fueron la clave para hacer frente a la dictadura en la década de 1970 a1980 (Azevedo, 2004). La progresividad dependió de la orientación local de grupos y liderazgo, a raíz de la importancia de la participación popular, la construcción de la auto estima individual, la emancipación y la propiedad de los problemas sociales y las soluciones expuestas por la Teología de la Liberación (Burdick, 1996). Las diferencias entre los discursos conservadores y acciones locales progresistas apoyan la diferenciación hecha por Azevedo (2004, p. 111), con el argumento de que la jerarquía de la Iglesia en Brasil tiene más "autoridad simbólica" que "la autoridad disciplinaria".
En el medio protestante y evangélico, personas con historia de lucha por la democracia y por justicia social se propusieron incluir el tema del SIDA en el cuadro de las luchas sociales que apoyaban, enfocadas en la "superación de la pobreza y de la exclusión de clase". Los entrevistados relataron la dificultad de poner el tema del SIDA en la agenda del Consejo Mundial de Iglesias de modo significativo hasta 1995 porque muchas personas afectadas por la epidemia no se encuadraban en esas clásicas definiciones de exclusión.

São Paulo ha sido el estado brasileño más afectado por la epidemia; y contó con el capital social y político de líderes de la lucha democrática y la posibilidad de innovar informado por el pensamiento técnico-científico. En el campo católico el Arzobispo de São Paulo, Don Paulo Evaristo Arns, fue citado unánimemente como un apoyo importante. Nominado cardenal en los años más duros de la dictadura, amparaba a los adeptos de la "teología de la liberación" (TL) que luchaban por el fin de las torturas y el restablecimiento de la democracia (Gaspari, 2002). Esa no era la actitud de toda la Iglesia Católica brasileña que polarizaba la respuesta al SIDA (Galvão, 1997; Parker \& Aggleton, 2003). Como discutió Mott (1985), en un extremo se situaba el cardenal del Río de Janeiro, Don Eugenio Sales, intransigente, acusador de los enfermos, y en el otro, estaba el "más magnánimo el Cardenal de São Paulo" que resaltaba la misión de reconfortar a los enfermos de SIDA como a todos los enfermos graves.

El acogimiento de enfermos, estimulado por los técnicos de la salud, fue realizado desde luego en los terreiros de matriz afro-brasileña, que eran más abiertos a los homosexuales bastante afectados por la epidemia. Muchos líderes religiosos resistieron al régimen militaren nombre de la democracia y apoyaron la respuesta no-gubernamental, y no sin falta de oposición y de barreras, el gobierno les proporcionó recursos técnicos y financieros. Un médico, que participó activamente en la construcción del primer programa contra el SIDA en Brasil, recordó que fue posible encontrar el respeto por los derechos humanos y la solidaridad en la atención dedicada a la enfermedad y la muerte con dignidad. Profe- 
sionales de la salud, incluyendo a muchos psicólogos del programa contra el SIDA, valoraban el humanismo entre los católicos en el gobierno y los que actuaron a través de las redes localmente enraizadas (capilaridade) de la Arquidiócesis. Basándose en los conceptos de "ecumenismo" y "solidaridad", los líderes religiosos y los programas de prevención de la salud co-organizaron las actividades de prevención y atención que ayudaron a disminuir el estigma asociada a la enfermedad.

El primer año en que se organizó el día Mundial del SIDA, tuvimos una ceremonia ecuménica en la Catedral, con Don Paulo y otras autoridades religiosas, del Candomblé, y con el rabino de los judios, que también se envolvió muy precozmente. (Médico de salud colectiva)

Profesionales de salud entrevistados recontaron que los grupos católicos, evangélicos, y protestantes que compartían la inspiración de la teología de la liberación, caminaron en São Paulo "muy rápido hacia una reducción de estigma y discriminación y a una actitud más progresista". Lo mismo se observaba entre líderes religiosos de diversos grupos espíritas y judíos, sacerdotes de Umbanda y Candomblé que fueron llamados a participar.

Asistencia y apoyo a las personas con SIDA, aún sin tratamiento disponible, fue el tema central de los líderes religiosos en la primera década de la epidemia. El tema fue tratado con discreción, rodeado de secretismo, pero no se le negó. De acuerdo con el testimonio de un sacerdote anciano, los primeros casos de sacerdotes y seminaristas con SIDA a mediados de la década de 1980 fueron tratados con el cuidado y la solidaridad:

Era 1988....Una señora, anciana, de 72 ó 73 años, en una reunión de agentes de la Pastoral se expresaba sobre el SIDA: "Padre, ¿es aquella enfermedad que le da a padre...?" [risas] . . . Lo que quiero remarcar fuertemente es una situación de confusión. No se comprendía bien la enfermedad, se tenía un miedo enorme, porque las personas morían en poco tiempo, entonces las personas eran muy reservadas... Una actitud humana $y$ cristiana es la solidaridad. Ella se impuso, ¿viste? Gracias a Dios, nosotros no tenemos más esas restricciones. Como se dice, la reprobación de ciertos comportamientos de la moral católica no le quita la dignidad de la persona. (Padre que participó del Pastoral de la Salud)

La solidaridad era, de todas formas, casi siempre regulada por la normatividad de las comunidades religiosas que la sustentaban. Algún tipo de adecuación a los principios religiosos de la congregación, iglesia o terreiro afro-brasileño era necesaria para ofrecer apoyo y cuidado. Las reglas del silencio eran comunes, por ejemplo, y de reclusión de miembros de la comunidad religiosa fue el caso sobre todo entre los líderes religiosos viviendo con el VIH, pero mucho menos común entre los seguidores de Umbanda y Candomblé, de acuerdo con los entrevistados.

Otro entrevistado, que fue vicario por nueve años, narró su primer contacto con la enfermedad y "la muerte de dos colegas" a mediados de los años 1980. El primero era seminarista que, cuando desarrolló el SIDA, consiguió resistir sin pedir ayuda, encerrado en su cuarto. Contó cómo fue chocante verlo por la última vez cuando salió para ser internado. El vicario no había oído nada hasta que descubrió el seminarista había muerto. La pregunta de "él murió de qué, era sólo para un grupo selecto de personas amigas... todo era desarreglado en esa época y sin mucho sentimiento de solidaridad". El entrevistado definió el segundo caso como un suicidio, "una salida" para la situación. "Él atravesó de cualquier forma la agitada avenida, fue llevado con vida al hospital. Un padre que vivía con él relató que oyó a dos médicos comentando que él tenía SIDA".

Informantes de todas las matrices religiosas concordaron que esa opción por el silencio se debía, en primer lugar, a la inseguridad sobre los modos de transmisión para evitar el pánico, caso se supiese que acogían enfermos con SIDA. La asociación de la epidemia con la promiscuidad e como una "peste gay" también indicaba la discreción. Como recuerda un sacerdote:

Frente a la inseguridad, pocas personas se disponían acoger portadores del virus. En 
este punto, Don Paulo tuvo gran influencia psicológica: Nosotros no podemos dejar de cuidar personas y no es porque nosotros no aprobamos la homosexualidad que vamos a dejar de tratarlas.

Los entrevistados coincidieron que de los que se involucraron de inmediato en los esfuerzos contra el SIDA fueron movilizados por la historial de haber conocido a alguien afectado por la enfermedad. Movilización institucional sucedió gradualmente y fue estimulada por las nociones de "solidaridad" y "compasión". Los relatos de los entrevistados y los documentos analizados trazan paralelismos en el sacerdocio y el "cuidador de las almas", "pastor" y la noción de "acogimiento" de los sufrientes en los primeros años de la epidemia, para ayudarles a "lidiar con la muerte" y "morir con dignidad". Al mismo tiempo, las iniciativas más politizadas utilizaron el concepto de la protección de los derechos. Muchas narraciones compararon las actividades de los líderes religiosos a los de la atención integral en salud, concebida como "el cuidado del cuerpo, del alma y de la ciudadanía".

Bajo la orientación, o más precisamente, con la "convocación a la acción" de los profesionales de los programas de SIDA a fines de los años 1980, adeptos a la matriz afro-brasileña y católicos, organizaron las primeras Casas de Apoyo para niños y adultos que viven con SIDA, que rechazados por las familias, eran acogidos en ellas. Grupos evangélicos con casas para internación de usuarios de drogas extendieron su trabajo a recibir enfermos de SIDA con ese perfil. O sea, los profesionales de salud, adeptos o no a alguna religión, comenzaban a dedicarse a la prevención y buscaban activamente a los liderazgos religiosos para ampliar el alcance de su trabajo. El "Grupo Religioso de Educación, Apoyo y Solidaridad" fue formado como un "grupo ecuménico" que reunía diferentes tradiciones religiosas para planear la actuación y capacitación de integrantes de las diversas religiones representadas. Entre 1988 y 1989, el Centro de Entrenamiento y Referencia de SIDA de São Paulo reunió sacerdotes afro-brasileños, luteranos, presbiterianos, católicos, judíos, mormones y kardecistas en talleres, ponencias, en la producción de cartillas y materiales informativos con un lenguaje apropiado para cada tradición religiosa. Religiosos católicos y protestante-evangélica se demoraron más en acercarse al tema de la prevención.

En síntesis, la primera década de la respuesta organizada por el estado en colaboración con la sociedad civil, consiguió validar el debate científico con religiosos, permitiendo la diseminación de informaciones correctas y la disminución de la discriminación de las personas que viven con VIH. La noción de la solidaridad y de la perspectiva de los derechos es un ejemplo de la concreción de la reforma de salud en el estado en el sentido de garantizar la el derecho a la salud universal e integral, incluso antes de que el Sistema Único de Salud (SUS) existiera. Ellos trabajaron con la religiosidad de aquellos que afrontaron con la epidemia de manera colaborativa junto con las autoridades del sistema de salud. Ese discurso religioso de afrontamiento estimulaba en los fieles un afrontamiento de estilo "colaborativo" y no "delegante".

Al final de la segunda década, la alianza más íntima entre el Programa Estadual de ETS/SIDA y los grupos religiosos pasó a ser resultado de iniciativas aisladas y bastante puntuales. Como discutieron Souza et al. (2012), debido a la presión política de los adeptos a religiones de matriz afro-brasileñas y de una nueva generación dedicada a promover la salud de la población negra en Brasil, apenas en 2002 se organiza el Grupo de Trabajo SIDA y Religiones (GT-Religiones). La noción de "inter-religiosidad", una innovación técnica, superó la noción de "ecumenismo", definiendo espacios y actividades para darle más énfasis a la prevención. La presencia católica como las actas de reuniones analizadas dejaron más claro - fue bastante más rara que en el inicio de la epidemia. La siguiente sección aclarará como se dio a cabo esta situación.

\section{La Respuesta Católica en São Paulo: Pastorialistas vs Canonistas}

Varios entrevistados católicos citaron un número significativo de padres que morían de SIDA en los primeros años de la epidemia, muchos procedentes de otras regiones de Brasil a 
São Paulo. Los números mencionados por los entrevistas varían, pero ellos consistentemente citaron alrededor de 50 líderes religiosos con SIDA. Un sacerdote que vivió por esta época narra el primer caso.

Él fue el primer padre que murió de SIDA aqui en São Paulo. Él era profesor antes de entrar en el seminario y fue internado en el hospital. . . yo puedo hablar de esa monja que debe haber recibido más de treinta casos ite das cuenta? . . hay uno siendo acompañado hasta hoy con 83 años. $Y$ yo tuve todo el cuidado de mantener el contacto normal, humano, amigo, fraterno. ¡Joven! llamó la atención, sobretodo del cardenal arzobispo y de la Pastoral de la Salud de la Arquidiócesis. Fue internado en un hospital público, y la reacción de los profesionales del hospital fue muy reservada, muy temerosa, de manera que el padre no duró mucho tiempo, falleció deprisa, así ocurría con todos los casos de la primera etapa. Y en el velorio muchas personas no se acercaron al féretro, que a propósito, estaba lacrado. A la hora de salir al entierro, el señor de la funeraria se rehusó a sujetar el asa del féretro por miedo de contagio. Y la familia estaba realmente profundamente chocada. Pero en la Iglesia fue acogido, acompañado normalmente. Éste es el primer caso. (Padre de la Pastoral)

Las autoridades católicas "pastorialistas", como mencionó por el entrevistado citado, preferían la actuación colaborativa y "ecuménica", "en solidaridad" con otras religiones en dirección al "bien común". Incentivaban la dedicación del "carisma" a las acciones sociales, organizaban comunidades eclesiales de base (CEB), pastorales temáticas (del trabajo, de la salud, entre otras) para diseminar los principios de la participación en la solidaridad. El estilo de afrontamiento colaborativo de la emergente epidemia del SIDA era uno de sus frentes de acción.

La religiosidad de las autoridades católicas más conservadoras fue lenta para accionar una respuesta al SIDA como una cuestión específica, y el debate sobre la misión de evangelizar era la cuestión clave. Como discutió Galvão (1997), ellos lidaron con el resurgimiento de la catequesis para abordar las crecientes acciones basadas en Teología de la Liberación (TL), mientras que se enfrentaron al crecimiento de grupos evangélicos en todo el país. Se organizaron los movimientos de renovación carismática para llegara seguidores con canciones efusivas, con rituales de curación de fe, y el uso de canales de radio y televisión concedidos por el Estado, que hasta hoy son inaccesibles a las religiones no-cristianas. Los entrevistados señalaron el alineamiento del arzobispo de Río de Janeiro con la posición oficial del Vaticano de Juan Pablo II. Otros católicos más canónicos con posiciones conservadoras sobre la epidemia, así como muchos médicos enfrentaron el surgimiento del SIDA en este período como algo restringido al universo moral o relacionado con el castigo divino, adoptaron un discurso que podría considerarse un estilo de afrontamiento delegante.

En el otro extremo estaban seguidores de la Teología de Liberación (TL). Este movimiento religioso reunió a diversas teologías cristianas que han surgido en América Latina, como uno de los sacerdotes entrevistados describió. Como discutió Perea (2004), muchos teólogos de la liberación fueron acusados de fomentar la formación de "células comunistas dentro de la Iglesia" porque organizaron las CEB con la lógica de las primeras comunidades de católicos, un modo de organización asociado a la inspiración socialista de sus opositores. Integrada a la fe cristiana, se concentra en la situación de pobreza y desigualdad social interpretada como un producto de estructuras económicas y sociales injustas y "concibe a las personas pobres y carentes no como un objeto de caridad, sino como sujetos de la liberación, solidaria, de su carencia". Su religiosidad es dedicada al cambio social y a la misión 'pastoralista', que "implica estar al lado del pueblo pobre". Definen la religiosidad de los canonistas como "vinculadas al derecho canónico de la Iglesia que resisten a la renovación". Los canonistas siempre fueron una preferencia de gobiernos políticamente conservadores de América Latina.

Estos dos extremos representan, por una parte, la posición oficial del Vaticano, la posici- 
ón canónica y hegemónica en Río de Janeiro, y en otra parte, y posiciones no-oficiales que prevalecían en los sectores semi-institucionales y diversos de la Iglesia y de la respuesta gubernamental al SIDA en São Paulo (Murray, Garcia, Muñoz-Laboy, \& Parker, 2011). La resistencia a una posición que fue más canónica y oficial también fue justificada por varios entrevistados, basadas en la misión específica de cada congregación, como en el caso de los Camilianos - una congregación dedicada a los enfermos-que se preocupaba por los sacerdotes y seminaristas con SIDA o actuado junto a los enfermos en las capellanías en hospitales públicos. ${ }^{11}$

La congregación religiosa a la que pertenezco establece que los miembros de la Orden deben estar dispuestos a dar sus vidas para ayudar a personas acometidas por molestias infecciosas. [Era] mi postura frente a la nueva enfermedad que apenas apareció en São Paulo . . . Entre los primeros casos habia un padre infectado por VIH. (Padre camiliano)

Padres y agentes pastorales que trabajaban con adultos y niños sin hogar, en contacto con trabajadores del sexo y usuarios de drogas, especialmente en las favelas, actuaban para diseminar informaciones sobre la enfermedad y la prevención en sus acciones sociales y en sus parroquias. La mayoría de ellos ya había "pre-

11 Para los que no conocen, la estructura jerárquica de la Iglesia está centralizada en el Papa que legisla a través de bulas y dirige el colegio de los obispos que tienen jurisdicción sobre los fieles del territorio de su diócesis, que incluye padres (párrocos y vicarios) que ejercen funciones en determinados locales y parroquias. La arquidiócesis es una diócesis importante, por motivos históricos o tamaño. El modo de funcionar de la estructura, entretanto, permite la agregación de misiones distintas. Por ejemplo, Congregaciones distintas (dirigidas por los Abades, cuyo nivel jerárquico equivale al de los obispos) organizan la formación de religiosos en su misión específica como actores de una sociedad civil más amplia. La misión de las congregaciones excede, por lo tanto, rituales compartidos por todos los católicos (la misa de los domingos, el rosario, las fiestas especiales, el bautismo, la comunión, la confirmación, el casamiento, la extremaunción a la víspera de la muerte). senciado el padecimiento y aislamiento" de personas que viviendo con SIDA. Muchos de esos activistas y voluntarios entraban, o incluso invadían, los gabinetes de la Secretaría de Salud exigiendo "más camas" o condiciones para ofrecer cuidados paliativos y "dignidad" a los que se enfermaban y morían. ${ }^{12}$

Vinculado al contexto hospitalario, traté la creación de una unidad para asistencia a niños con VIH en la clínica infantil. El directorio de la clínica se rehusó decisivamente. Se decía que si se internasen niños portadores de VIH, la población no internaría más niños en la clínica. (Padre y capellán)

Porque participaban en la resistencia democrática contra la dictadura, las comunidades eclesiales de base acumularon un repertorio político para comprender los principios del estado secular establecido en la Constitución de 1988. Según varios entrevistados, los católicos progresistas activos en las diversas estructuras de la Iglesia, en las ONGs o en el gobierno, contribuyeron para ampliar el respeto a la libertad de credo y hasta de la orientación sexual en los espacios de formulación de políticas públicas. Actores religiosos y gubernamentales que actuaban concibiendo la participación de modo semejante: "como consulta y envolvimiento en el trabajo de base en la movilización y en la proposición de acciones locales -en el caso de las ETS/SIDA de la iglesia de base- y al mismo tiempo, aumentar la ciudadanía y promover la emancipación". Programas de SIDA de diversos municipios también aceptaban el financiamiento de organizaciones no-gubernamentales con presupuesto público, con base en el principio de la participación y de la descentralización, una práctica que se mantiene hasta la tercera década de la epidemia (Garcia \& Parker, 2011). Según los entrevistados, las casas de apoyo organizadas durante el siguiente período y las organizaciones no-gubernamentales dedicadas a enfrentar la epidemia, las iniciativas de los líderes religiosos pastoralistas emer-

12 http://www.forumaidsp.org.br/publicacoes_ed2/ assistencia.htm (Accedido el 20 de mayo de 2009). 
gieron, "debido a la necesidad." En un período en que el Sistema Único de Salud aún no existía, y los hospitales fueron lentos para reaccionar adecuadamente, la Pastoral de la Salud creó los incentivos para movilizar voluntarios "cada uno por su propio camino", apoyando la autonomía. Uno de los fundadores del programa de SIDA en São Paulo explicó:

Cuando se presentó el proyecto de casas de apoyo y las instituciones candidatas, hubo muchas reacciones... "Espera, ¿Qué es eso? un sacerdote de religión afro-brasileña [coordinador casa de apoyo], ¡No es posible!...”” Pero las autoridades [gubernamentales] acabaron concordando. El tema siguiente: ¿Cómo me transferirás el dinero? Y no fue la primera discusión. En 1988, conseguimos el primer contrato formal de transferencia de dinero del Estado de São Paulo. Muchas discusiones con el sector jurídico, con el sector político, al que le parecía absurdo, hacer un contrato con una travesti (Brenda Lee) que tenía una casa [de apoyo] donde vivian profesionales del sexo. [En ese contexto...] la Iglesia debería ser vista como cualquier otra organización de la sociedad civil con iniciativas para amparar, reducir el impacto social y cubrir lo que el Estado no podía o no tenía como proveer. (Médico sanitarista)

La colaboración del Estado con la Iglesia Católica fue, desde entonces, fuertemente basada en la noción de que "la iglesia consigue llegar a varios lugares donde el poder público e incluso el privado no consigue, ¿no?”, como recuerda un activista entrevistado de la Pastoral del SIDA, un argumento que relataron informantes en otros estados también (Garcia, Muñoz-Laboy, \& Parker, 2011; Murray et al., 2011). Apoyadas directamente por la Arquidiócesis de São Paulo o por misionarios, se abrieron casas de apoyo para adultos y niños viviendo con VIH, especialmente los más necesitados "desde el punto de vista socio-económico"13-una forma de economía-política usada para interpretar la opresión y la

13 http://www.alivi.org/Alivi/quemsomos.htm (Accedido el 20 de mayo de 2012). solidaridad. Valorizada por entrevistados de todas las religiones, la Arquidiócesis de São Paulo de este período, dejó como legado una organización social sin fines lucrativos y actuante en defensa de los derechos de las personas viviendo con VIH, acogiendo a su manera a todas las religiones. Veinticinco años después, esa organización aún desarrollaba acciones en el campo de la salud, de la educación contra la discriminación sexual y de género, ofreciendo atendimiento jurídico, y distribuyendo alimentación.

Muchos entrevistados también cuentan la historia del Fraile Franciscano que era portador de VIH que, al asumir una identidad homosexual, fundó una $\mathrm{ONG}$.

El fraile quería algo más técnico y cientifico. Él quería un trabajo que valorizase al portador de VIH/SIDA como un ser humano, que no tuviese la muerte como el único camino de su vida sufrida. Su gran preocupación era no alimentar en el seropositivo el estigma de ser un "muerto social". Quería traerlo de vuelta a la vida... El Centro surgió en una época de pánico. Después, hubo un trabajo fuerte de educación, politica . . . En un primer momento, actuamos como representantes del portador de VIH. Pero, a partir de un cierto punto . . . el propio portador debe protagonizar su vida... sus derechos, ocupar los espacios que le caben, lo que le es debido. (Profesional de salud en la ONG)

Creada y apoyada por Franciscanos, la organización ejerció un papel importante en la construcción de la respuesta no-gubernamental. Con el tiempo, los trabajadores del centro exigieron la superación de la beneficencia y la creación de multiplicadores y protagonistas, y que ocupasen un lugar al lado del poder público. Se puede observar que, como en los servicios de salud especializados en SIDA, los usuarios rechazados y estigmatizados trataban el espacio como una extensión de su casa, independiente de su credo personal. Una asistente social insistió tanto en su declaración que religiosos comenzaron a decir "Mira, no somos nosotros quienes tenemos que cuidar de tu vida, pero eres tú quien debe dirigirla y no la institución". 
En un informe Quinquenal 1985-1989 de la Arquidiócesis de São Paulo al Vaticano, se incluyó por primera vez "la acción pastoral en respuesta al SIDA". En un fragmento, el informe incluye un proyecto propio de la en São Paulo:

En los últimos años, São Paulo se volvió un centro de enfermos de SIDA de América Latina. La iglesia de São Paulo no se omitió en este campo. Desarrolló un amplio trabajo de concientización de la población sobre la gravedad de la molestia, sus vías de transmisión y cómo evitar su difusión. Promovió y participó en debates y días de estudios en varios niveles, incluso de carácter ecuménico. Los párrocos y las demás instituciones eclesiales fueron estimulados a dar su colaboración. (Arquidiócesis de São Paulo, 1990, p. 103)

Fue en ese período histórico que la TL fue condenada dos veces por el entonces Cardenal Joseph Ratzinger ${ }^{14}$, alcalde de la Congregación para la Doctrina de la Fe. En 1989, la acción papal redujo el territorio de la Arquidiócesis de São Paulo dividiéndola en cuatro nuevas diócesis. Los entrevistados fueron unánimes al afirmar que la postura de Don Paulo y su iglesia de base frente a la epidemia del SIDA fue la gota de agua para la decisión de dividir la diócesis bajo su responsabilidad. Las organizaciones sociales religiosas y la iglesia de base lideraban un movimiento de transformación de la religiosidad, en red con otras organizaciones con quienes aprendían a comprender y a enfrentar la epidemia.

Fue cuando el debate sobre la prevención y el uso de preservativos comenzó a tomar cuerpo y el Vaticano amplió su acción política en el campo del SIDA. La escena presenciada por el padre octogenario es destacable:

No me acuerdo el año... En el primer congreso sobre el SIDA realizado en el Vaticano estaba un padre africano con SIDA, y el cardenal que presidia mandó a retirarlo de la sala. Después hubo una reacción [contra la expulsión] y él lo mandó a llamar. En ese mismo congreso, el hoy cardenal [X] dijo que si en una pareja uno tuviese SIDA

14 Más adelante el Papa Benedicto XVI. y quisieran mantener relación sexual, que uno de los dos esté dispuesto a contagiarse con SIDA, pero que no usase preservativo. (Padre de Pastoral)

Mientras municipios brasileños y estados nacionales, como el Vaticano, seguían negando la prioridad y emergencia de la epidemia, con negligencia al derecho a la prevención y a la salud integral y, por lo tanto, aumentando la vulnerabilidad programática de los socialmente más vulnerables, lo mismo hizo la línea más 'canonista' que entró fuerte en el debate sobre prevención.

\section{Las Controversias sobre los Condones: "Se Rompe con Menos Agujeros de los que Existen en la Monogamia y Fideli- dad entre Parejas"}

Un elemento contextual menos común en otros países, el diálogo entre el gobierno y la sociedad civil en la primera década de la epidemia incluyó diversas organizaciones de la Iglesia Católica, que reconocieron la contribución de la ciencia y de los referenciales ético-políticos de la reforma sanitaria. Muchos informantes recordaron las iniciativas de la CNBB de la época, que tenía un posición oficiosa más favorable con relación al condón. Uno de los organizadores del programa de SIDA describió esas posiciones así:

La primera vez que oí [miembros de la Iglesia] recomendando condones, eran personas que trabajaban con niños de la calle. Entre 88 y 89, en un programa [de TV estaba] Don Paulo. Como estaba previamente combinado, el presentador preguntaba ¿Cuáles eran las recomendaciones para la prevención? ¿Qué es lo que se debia hacer, incluir información, etc.? ¿Y el uso del condón?' Don Paulo no usó la palabra condón: "Tenemos que apoyar... Blablablá blablablá. La Iglesia está orientada a apoyar a las autoridades sanitarias en la forma en que fue presentada por el Dr. Paulo Teixeira" [del Programa de SIDA] . . Creo que en 92, la Pastoral de la Juventud, por decisión de la CNBB, adoptó el SIDA como tema a tratarse en las comunidades de jóvenes. En 
esa época, nosotros no teníamos cualquier posibilidad de apoyar financieramente, entonces quedó una alianza mucho más de carácter político. (Médico sanitarista)

Padres y o bispos en otros estados, entretanto, reforzaban su posición canónica, y enfatizaban que ser homosexual era pecado, el valor de la monogamia y del compromiso conyugal, predicando la abstinencia y la fidelidad como el mejor camino para evitar el SIDA. Sin el apoyo de Don Paulo, el conflicto pasó a ser abierto.

Muchos de los entrevistados citaron la controversia sobre el castigo del Padre Valeriano, que anunció la producción de un vídeo que cuestionaba la posición del Vaticano, irreductiblemente contra los condones. El padre fue punido porque en una entrevista a un diario defendió el uso y la distribución de los condones. ${ }^{15}$ Varios entrevistados recordaron que Don Eugenio Sales (RJ) produjo una nota de repudio firmada también por Don Claudio Hummes, el nuevo Cardenal Arzobispo de São Paulo, una reacción interpretada como una intervención directa del Vaticano y de sus "representantes y espías en Brasil". Informantes nos contaron que en la Conferencia de los Obispos invitaron a "alguien de Roma" para hablar sobre cómo la Iglesia estaba lidiando con el SIDA mundialmente. En las palabras de un padre misionario:

Vino no sólo para eso: vino a fiscalizar una iglesia de Brasil que estaba transmitiendo el uso del preservativo. El cardenal de Río de Janeiro, que nosotros llamamos como mafioso de la Iglesia Católica en Brasil, reportaba todo lo que ocurría aquí en Roma. Entonces preparamos este panfleto, el obispo estaba con nosotros y lo llevó al directorio de la CNBB para ver si ellos lo aprobaban. Lo aprobaron, se imprimió. Cuando vino el enviado de Roma, mandó a retirar el panfleto y pidió que la CNBB se retractase, porque nosotros dijimos: "Eso fue aprobado por la CNBB". La CNBB dijo que nun-

15 Esa polémica repercutió en la prensa brasileña y extranjera, como se ilustra en los reportajes de Cafardo (2000), "Is Prete Difende" (2000), Jordan (2001) y "Religioso diz que CNBB" (2000). ca había visto el material y el obispo, que acompañaba ese trabajo, apoyó a la CNBB. Fue un desastre. (Padre misionario)

Activistas de la ONG hicieron una manifestación en la puerta de la casa del arzobispo que aceptó la comisión, “y todo murió allí”, cuenta el entrevistado. La comisión que trabajaba con la CNBB fue deshecha y substituida "en la silenciosa por otra comisión vaticanista". La posición pública, sin embargo, era menos clara: "Roma no quiere perder el diálogo con los gobiernos", según un padre entrevistado que explicó que la Iglesia temía la reacción del debate abierto en los medios y prefería no ampliar la controversia.

En 2003, en una "carta abierta" para el Programa Nacional de ETS/SIDA del Ministerio de Salud, la presidencia de la CNBB defiende la atención de la Iglesia y el apoyo a los enfermos, en las iniciativas de prevención y en la lucha contra el perjuicio sufrido por las personas afectadas por la epidemia y difunde su punto de vista sobre la sexualidad. Ofrece una interpretación alternativa de pensamiento técnico-científica sólo acerca de cómo abordarla prevención. Cuestionando la efectividad de los condones y evocando la existencia de otros "métodos eficaces", defiende un orden moral dogmática para educarla juventud, una "antropología de la sexualidad", que teme quela educación sexual integral y añade que sería estimular el comportamiento sexual sin límite se irresponsable (CNBB, 2003).

A partir de ese momento, varias autoridades eclesiásticas estimularon controversias públicas sobre la eficacia del preservativo divulgando en textos que los condones formaban agujeros (que se rompían). Un sacerdote entrevistado comenta: "se rompe con menos agujeros de los que existen en la monogamia y fidelidad entre parejas". A pesar de todo, la respuesta oficiosa de la Iglesia de base en São Paulo siguió defendiendo "el evangelio del buen samaritano" como comenta un agente de la Pastoral entrevistado, insistiendo que es papel

de todo cristiano, de todo ser humano, de dar información correcta y hablar de todo sobre el SIDA. ¡Todo! El padre no está allí, el obispo no está allí. ¿Entendió?. Al nivel 
local el trabajo continuó: "de aclaración, de exigir politicas que favorezcan esa formación, ese conocimiento y puedan ayudar a las personas y, sobretodo, a la juventud, a preservarse, a precaverse" (Padre de parroquia).

El Programa Nacional de SIDA, que caminó en sintonía con la respuesta al SIDA en São Paulo desde los años 1990 (Berkman et al., 2005; Teixeira, 1997, 2003) entra fuerte en el debate. La acción más emblemática fue la "Campaña - por el preservativo no pasa nada", cuya imagen central mostraba un condón transformado en un acuario con peces nadando, sintetizando el mensaje "Use y confie". ${ }^{16}$ Informaciones y orientación se diseminaron sobre la seguridad del preservativo y la manera correcta de usarlo consistentemente.

\section{Lecciones de la Respuesta al SIDA sobre el Afrontamiento Religioso}

La contribución de los líderes religiosos en São Paulo a la respuesta social exitosa al SIDA no debe ser ignorada o considerada como mínima. La historia relatada aquí es la versión de los participantes de esa respuesta articulada a los programas gubernamentales, un límite de este estudio. De todas formas, la dinámica de la religiosidad y del afrontamiento religioso puede describirse también en la perspectiva de las autoridades religiosas, un estilo de afrontamiento influenciado por una dimensión institucional y política, comprensible sólo y en do más allá de la dimensión individual estrictamente enfocada en comportamiento. En otras palabras, en este estudio observamos la influencia de la política en religiosidad y en el estilo de afrontamiento adoptado (personal e institucional), que es compartido entre los fieles religiosos.

En síntesis, desde los años 1980 adeptos de varias religiones como parte de la sociedad civil contribuyeron a la respuesta en São Paulo con

16 Se puede asistir en el site: http://www.aids.gov. br/campanha/carnaval-2004-pela-camisinha-nao-passa-nada-use-e-confie (Accedido en mayo de 2012). programas gubernamentales dedicados a garantizar el acceso y el derecho a la salud integral de las personas viviendo con VIH y a la prevención centrada en el use de condones. Ese movimiento fue significativo, como discutió Correa (1997): denunciar la negligencia gubernamental, la sostenibilidad de la protección de la ciudadanía para las personas que viven con VIH, y el debate público sobre la importancia de la solidaridad siempre fueron papeles de la sociedad civil.

A su modo, los religiosos que participaron de este estudio contribuyeron a superar la negación de la emergencia de la epidemia (denial) desde la primera década, cuando el SIDA alcanzaba con mayor prevalencia hombres homosexuales y usuarios de drogas. Ellos integraron lo que aprendían al discurso religioso tradicional y a su religiosidad personal, transformándola frente a esta situación inesperada. De este modo, desafiaron la religiosidad institucional y un estilo de afrontamiento estimuló la negación y la discriminación de los enfermos, como fue el caso de los católicos en São Paulo que vivieron con un debate interno tenso, enfrentando aislamiento o castigo infligido por los escalones más altos de la jerarquía de la Iglesia alineado con el Vaticano. El compromiso de los humanistas católicos con diversos movimientos sociales, en sinergia con los cristianos de varias denominaciones inspiradas por Teología de la Liberación, construyó un estilo de afrontamiento religioso que fue necesariamente colaborativo-que fue productivo para responder a una epidemia crítica y emergente. Ellos se distanciaron de la mayoría de los cristianos, los científicos y los profesionales de la salud que actuaron basados en su religiosidad y morales, ignorando la evidencia científica. ${ }^{17}$ Estos religiosos promovieron lo que podríamos considerar como estilo delegante de afrontamiento: Dios puniría a los promiscuos con el SIDA y salvaría a los adeptos a la moralidad establecida por reglas canónicas. El "mal comportamiento" produciría la infección y la enfermedad.

Muchos católicos, que durante los primeros años de la epidemia participaron en el debate

17 Ignoraron estudios epidemiológicos irrefutables sobre los modos de transmisión del virus aislado. 
interno de la Iglesia, permanecieron por más de dos décadas asesorando a las llamadas comunidades eclesiales de base (iglesias de base) y a los programas gubernamentales de SIDA. Otros reconstruyeron "su misión," después que los disidentes fueron punidos distanciándose del discurso oficial e institucional conflictivo sobre el afrontamiento. Como Perea (2004) notó, esto ocurrió porque se reconocieron con el derecho de hablar como individuos en la construcción de los espacios cotidianos y ejercer su libertad de conciencia.

\section{Como la Vulnerabilidad al Enfermedad, el Afrontamiento Religioso tiene Dimensiones Personal, Institucional y Socio-Política}

La literatura sobre afrontamiento reconoce la influencia de la cultura y su poder de modelar evaluaciones de situación, sistemas de orientación de las personas en el mundo, así como el poder de privilegiar cuáles estrategias de afrontamiento enseñar (Faria \& Seidl, 2005). Los datos de este estudio confirman nociones que todavía no han sido el foco de la mayoría de los estudios sobre afrontamiento religioso. Posicionado en una perspectiva basada en los derechos humanos y constructivista social de la psicología social de la salud (V. Paiva, 2012a, 2012b), este artículo tuvo como objetivo ampliar este enfoque para incluirlas dimensiones políticas e institucionales que contextualizan el afrontamiento religioso.

Este estudio está en línea con varios académicos que observan cómo los brasileños afrontan con la regulación dogmática (Duarte, 2005; Duarte, Gomes, Jabor, \& Luna, 2006; Garcia et al., 2009; Martins, 2009). En otras palabras, las convicciones religiosas hacen parte de sus decisiones en el ámbito privado, con autonomía razonable contralo que dicta la doctrina (Duarte, 2005, 2006; Martins, 2009). Con las diferentes visiones del mundo implicadas en los rituales y creencias, por lo tanto, no explica totalmente el comportamiento de los miembros de grupos religiosos, como se discutió anteriormente (V. Paiva, Garcia, Santos, Terto, \& Munoz-Laboy, 2010).
Si este fenómeno se ha observado entre los seguidores religiosos, la historia de afrontamiento en las respuestas religiosas al SIDA presentadas en este artículo permítenos observarlo que sucede entre las autoridades religiosas, clericós y sacerdotes que, a su vez, producen discursos públicos de afrontamiento son disponibles para los adherentes de cada tradición religiosa.

En este proceso, las acciones del "sujeto religioso", como un agente de su religiosidad personal y un actor histórico, recrea el discurso oficial de la autoridad para que sea más congruente con su/ su propia experiencia. Esto también se observó entre los protestantes por Watanabe (2005) y entre los jóvenes de diversas religiones por Silva, Santos, Carli y Paiva (2008). No sólo las decisiones y acciones de las autoridades religiosas (por ejemplo, sacerdotes, educadores, reverendos, pastores, diáconos, líderes religiosos afro brasileños) reflejan sus propias subjetividades cognitivas y emocionales, como se discute en la literatura sobre el afrontamiento religioso, pero también configuran significados culturales contextualizados por los procesos sociales y políticos. La religiosidad de los clérigos y líderes religiosos activos en sus comunidades, que fueron los principales actores en la construcción de una respuesta al SIDA en São Paulo, como hemos visto, está marcada por el contexto socio-político en el que las perspectivas del humanismo y de los derechos humanos se fortalecieron en los programas de salud gubernamentales aliados con la sociedad civil.

No hay, por lo tanto, una respuesta simple a la pregunta de Defert (1996) presentada en la introducción: profesionales de la salud deben temer la intervención religiosa o considerar una alianza con ella. La lección que podemos aprender de este proceso histórico es que los profesionales de salud pública deberían prestar atención a la religión viva en el cotidiano de las personas, o sea, a la religiosidad que será intersubjetivamente movilizada en cada contexto social e institucional (comunitario, local, nacional, internacional). Tomando en cuenta la religiosidad de los adeptos y fieles en las comunidades, en las escuelas y locales de trabajo donde realizan programas de promoción de la salud o de asistencia 
social, es tan importante cuanto la religiosidad vivida por los líderes religiosos (y no sólo sus discursos acerca de principios).

Aun que muchos líderes religiosos son políticamente y éticamente llevados a representar la tradición y el dogma, a veces a costa de los derechos humanos de las personas enfermas, la interrogación directa del dogma por agentes del gobierno crea debates controversiales que por lo general no resultan en la comprensión mutua, especialmente cuando se trata de la sexualidad. Esto hace el proceso difícil o incluso paraliza a los funcionarios de salud con la obligación de promover y proteger el derecho a la salud de los ciudadanos de un estado secular.

La religión vivida, que se experimenta en la vida cotidiana de cada persona contextualizada por el escenario cultural e la política local, ha sido una forma de abordar este estancamiento. Esta perspectiva permite la interacción de los clientes, trabajadores de salud y las autoridades religiosas, cuya religiosidad también es el resultado de las interacciones diarias e intersubjetivas (V. Paiva et al., 2010). Según lo expresado en el relato de uno de los sacerdotes católicos entrevistados:

Digo siempre: "Hice el voto de castidad, hace 28 años que soy padre, pero si no renuevo todos los días mi opción de valores evangélicos (la castidad, la pobreza y así en adelante), el mundo me traga vivo". Porque estos valores no dependen sólo de la persona, pero esta persona vive dentro del mundo, de una sociedad, y lo que para nosotros son valores evangélicos, para la sociedad no son valores. Para la sociedad, dice: "si tengo relaciones con uno, dos, o mil, da lo mismo; yo me siento bien, satisfecho, y listo". Entonces debemos llevar adelante los discursos de esos valores con los pies sobre el suelo. Y no pensar que el hombre, sólo porque fue bautizado, será santo. O no pensar que en el día que fui ordenado padre, me vuelvo un ángel. (Padre misionario)

Similar a las tradiciones religiosas que son menos centralizadas, se debe distinguir, por lo tanto, "la respuesta católica" de la "respuesta de la Iglesia Católica", que en Brasil debería estar en plural. Perea (2004) incluye en la primera a los actores de la sociedad que de dan sentido al catolicismo alineándolos a los derechos humanos en los diversos aspectos de la vida en que ellos se presentan; la segunda está en las normas creadas y sistematizadas a través de instancias burocráticas, que los informantes llamaron "canónicos". Padres, arzobispos y capellanes que actúan con base en interpretaciones más abiertas al debate de los derechos, en especial de los derechos sexuales y reproductivos, pueden traer contribuciones significativas especialmente cuando la Iglesia misma acepta que ha sido afectada por el SIDA (Transferetti, 2001, 2005).

En diferentes contextos, en otros países, que no tienen las mismas circunstancias históricas contextualizan las "respuestas" católicos brasileños (plural) al SIDA (simultáneamente enfrentar la dictadura y tener el debate sobre la reforma sanitaria, o ser testigo de la producción de una teología nativa, como Teología de la Liberación), el afrontamiento también está asociado con la visión política de cada misión religiosa (Seffner, Garcia, Muñoz-Laboy, \& Parker, 2011). Discursos y prácticas de una religiosidad más canonista inspiraron un estilo de delegante de afrontamiento, la discriminación contra las personas afectadas por la epidemia del SIDA y el aumento de la vulnerabilidad individual y social a la enfermedad. Por ejemplo, aumentaron la vulnerabilidad a la infección entre las mujeres casadas, y consecuentemente de sus hijos, confiando en los discursos de la monogamia y la fidelidad e sus maridos.

Cada vez que preguntan: ¿Usted es a favor o contra el uso de preservativo? Existen dos éticas: una de principio, otra de responsabilidad. La ética de principio dice que uno no debe andar en la calle contra el tráfico. Pero vamos a suponer que en un momento de distracción usted no vio la placa, no percibió y estaba distraído y entró, alli está la ética de responsabilidad, toma cuidado para no abollar el auto de nadie, para no atropellar a nadie, así se aplica el tema del preservativo. (Activista de una comunidad eclesiástica de base que promueve el uso de los condones) 
El estudio psicosocial del afrontamiento religioso se beneficiaría de abordar cuestiones tales como la relación entre la sexualidad y la religión, que están directamente relacionados con el SIDA, y que son parte de la experiencia en la vida cotidiana. Personas religiosas en cualquier posición-como fieles seguidores o como parte de la autoridad-son las personas afectadas por sus contextos socio-políticos y culturales. Una psicología social de la religión que considere más importante la construcción histórica de los discursos podría recurrir a símbolos cosmológicos compartidos que resuenan en la vida cotidiana, dando sentido a las dimensiones emocionales y cognitivos del afrontamiento y sus estilos, teniendo en cuenta que la religiosidad y el afrontamiento religioso tienen personal e institucional dimensiones, inextricablemente afectadas por sus contextos culturales y políticos. Las experiencias de quienes participaron en la primera respuesta al SIDA en Brasil pueden proporcionar un mayor conocimiento de la práctica de la psicología.

\section{Referencias}

Arquidiocese de São Paulo. (1990). Relatório Quinquenal 1985-1989: Vol. 6. São Paulo, SP: Autor.

Ayres, J. R. C. M., Paiva, V., \& França, I., Jr. (2010). From natural history of disease to vulnerability: Changing concepts and practices in contemporary public health. In R. Parker \& M. Sommer (Eds.), Routledge Handbook in Global Public Health (pp. 98-107). London: Routledge.

Ayres, J. R. C. M., Paiva, V., \& França, I., Jr. (2012). Conceitos e práticas de prevenção: Da história natural da doença ao quadro de vulnerabilidade e direitos humanos. In V. Paiva, J. R. Ayres, \& C. M. Buchalla (Orgs.), Vulnerabilidade e direitos humanos - Prevenção e promoção da saúde: Livro I. Da doença à cidadania (pp. 71-94). Curitiba, PR: Juruá.

Azevedo, D. (2004). A Igreja Católica e seu Papel Político no Brasil. Estudos Avançados, 18(54), 109-120.

Berkman, A., Garcia, J., Munoz-Laboy, M., Paiva, V., \& Parker, R. (2005). A critical analysis of the Brazilian response to HIV/AIDS: Lessons learned for controlling and mitigating the epide- mic in developing countries. American Journal of Public Health, 95(7), 1162-1172.

Burawoy, M. (2009). The Extended Case Method: Four countries, four decades, four great transformations, and one theoretical tradition. London: University of California Press.

Burdick, J. (1996). Looking for God in Brazil: The progressive Catholic Church in urban Brazil's religious arena. Berkeley, CA: University of California Press.

Cafardo, R. (2000, 7 jul.). Ato em SP apóia padre pró-camisinha. Estadão. Recuperado em 7 de julho de 2000, de http://www.estadao.com.br/agestado/nacional/2000/jul/07/276.htm

Centro de Referência Técnica em Psicologia e Políticas Públicas. (2008). Referências técnicas para a atuação do(a) psicólogo(a) nos Programas de DST e AIDS. Brasília, DF: Conselho Federal de Psicologia.

Centro de Referência Técnica em Psicologia e Políticas Públicas. (2009). Práticas Emergentes e Inovadoras de psicólogos(as) no campo das DST/ AIDS: Vol. 1. Práticas em Psicologia e Políticas Públicas. Brasília, DF: Conselho Federal de Psicologia.

Chesnut, R. A. (1997). Born again in Brazil: The Pentecostal boom and the pathogens of poverty. Piscataway, NJ: Rutgers University Press.

Coates, T., Temoshok, L., \& Mandel, J. (1984). Psychosocial research is essential to understanding and treating AIDS. American Psychologist, 39, 1309-1314.

Conferência Nacional dos Bispos do Brasil. (2003, 09 dez.). Declaração da Presidência da CNBB sobre a "Carta aberta" do Programa Nacional de DST e Aids, do Ministério da Saúde. Recuperado em 22 de abril, 2013, de http://www.zenit. org/pt/articles/declaracao-do-episcopado-brasileiro-sobre-carta-aberta-do-programa-nacional-de-dst-e-aids

Correa, S. (1997). A solidariedade como solução. Boletim da ABIA - Associação Brasileira Interdisciplinar de AIDS, 37.

Defert, D. (1996). AIDS as a challenge to religion. In J. Mann \& D. J. M. Tarantola (Eds.), Aids in the world II (pp. 447-452). New York: Oxford University Press.

Duarte, L. F. D. (2005). Ethos privado e justificação religiosa: Negociações da reprodução na socie- 
dade brasileira. In M. L. Heilborn, L. F. D. Duarte, C. Peixoto, \& M. L. Barros (Orgs.), Sexualidade, família e ethos religioso (pp. 137-176) Rio de Janeiro, RJ: Garamond Universitária.

Duarte, L. F. D., Gomes, E. C., Jabor, J., \& Luna, N. (2006). Família, reprodução e ethos religioso: Subjetivismo e naturalismo como valores estruturantes. In L. F. D. Duarte, M. L. Heilborn, M. L. Barros, \& C. Peixoto (Orgs.), Família e religião, (pp. 15-25). Rio de Janeiro, RJ: Contra Capa.

Faria, J. B., \& Siedl, E. M. F. (2005). Religiosidade e enfrentamento em contextos de saúde e doença. Revisão de literatura. Psicologia: Reflexão e Critica, 18(3), 381-389.

Farmer, P. (1999). Pathologies of power: Rethinking health and human rights. American Journal of Public Health, 89, 1486-1496.

Galvão, J. (1997). As respostas religiosas frente à epidemia de HIV/AIDS no Brasil. In R. Parker (Org.), Politicas, instituições e aids: Enfrentando a epidemia no Brasil (pp. 109-134). Rio de janeiro, RJ: Jorge Zahar.

Garcia, J., Muñoz-Laboy, M., Almeida, V. de, \& Parker, R. (2009). Local impacts of religious discourses on rights to express same-sex sexual desires in periurban Rio de Janeiro. Sexuality Research and Social Policy, 6(3), 44-60.

Garcia, J., Muñoz-Laboy, M., \& Parker, R. (2011). Vulnerable salvation: Evangelical Protestant leaders and institutions, drug use and HIV and AIDS in the urban periphery of Rio de Janeiro. Global Public Health, 6(Suppl. 2), S243-S256.

Garcia, J., \& Parker, R. G. (2011). Resource mobilization for health advocacy: Afro-Brazilian religious organizations and HIV prevention and control. Social Science \& Medicine, 72(12), 1930-1938.

Garrido, P. B., Paiva, V., Nascimento, V., Souza, J. B., \& Santos, N. (2007). Aids, estigma e desemprego: Implicações para os serviços de saúde. Revista de Saúde Pública, 41(Supl. 1), 72-79.

Gaspari, E. (2002). A ditadura escancarada. São Paulo, SP: Cia das Letras.

Gough, B. (2007). Coming out in the heterosexist world of sport: A qualitative analysis of web postings by Gay athletes. Journal of Gay and Lesbian Psychotherapy, 11(1-2), 153-174.

Govender, K. (2011). The cool, the bad, the ugly, and the powerful: Identity struggles in schoolboy peer culture. Culture, health \& Sexuality, 13(8), 887-901.

Gruskin, S., \& Tarantola, D. (2008). Health and human rights: Overview. In K. Heggenhougen \& S. Quah (Eds.), International Encyclopedia of Public Health (Vol. 3, pp. 137-146). San Diego, CA: Elsevier.

Gruskin, S., \& Tarantola, D. (2012). Um panorama sobre saúde e direitos humanos. In V. Paiva, J. R. Ayres, \& C. M. Buchalla (Orgs.), Vulnerabilidade e Direitos Humanos. Prevenção e Promoção da Saúde: Vol. 1. Da doença à cidadania (pp. 23-42). Curitiba, PR: Juruá.

Is prete difende $\mathrm{i}$ preservativi la chies alo punisce. (2000, 5 di luglio). CNN Italia. Retrieved September 12, 2000, from http://www.cnnitalia. it/2000/MONDO/amerlatina/07/04/prete/

Jordan, M. (2001, February 21). Brazil's unconventional AIDS fight. The Wall Street Journal, p. I-IV.

Kian, E. M., \& Anderson, E. (2009). John Amaechi: Changing the way sport reporters examine Gay athletes. Journal of Homosexuality, 56(7), 799818. doi: 10.1080/00918360903187788

Mann, J., \& Tarantola, D. J. M. (Eds.). (1996). Aids in the world II. New York: Oxford University Press.

Martins, A. D. (2009). Catolicismo contemporâneo: Tratando da diversidade. In E. C. Gomes (Org.), Dinâmicas contemporâneas de fenômeno religioso na sociedade brasileira (pp. 125-146). Aparecida, SP: Ideias e Letras.

Mott, L. (1985). Aids: Reflexão sobre sodomia. Comunicações do ISER, 17, 32-41.

Murray, L. R., Garcia, J., Muñoz-Laboy, M., \& Parker, R. G. (2011). Strange bedfellows: The Catholic Church and Brazilian National AIDS Program in the response to HIV/AIDS in Brazil. Social Science \& Medicine, 72(6), 945-952.

Paiva, G. J. (1998). AIDS, Psicologia e religião: O estado da questão na literatura psicológica. $P s i$ cologia: Teoria e Pesquisa, 14(1), 27-34.

Paiva, G. J., Zangari,W., Verdade, M. M., Machado de Paula, J. R., Faria, D. G. R., Gomes, D. M., ...Gomes, A. M. A. (2009, jul./set.). A Psicologia da Religião no Brasil. Psicologia: Teoria e Pesquisa, 25(3), 441-446.

Paiva, V. (2008). A psicologia redescobrirá a sexualidade? Psicologia em Estudo, 13, 641-651. 
Paiva, V. (2012a). A dimensão psicossocial do cuidado. . In V. Paiva, J. R. Ayres, \& C. M. Buchalla (Orgs.), Vulnerabilidade e Direitos Humanos. Prevenção e Promoção da Saúde: Vol. 2. Entre indivíduos e comunidade (2. ed., pp. 41-72). Curitiba, PE: Juruá.

Paiva, V. (2012b). Cenas da vida cotidiana: metodologia para compreender e reduzir a vulnerabilidade na perspectiva dos direitos humanos. In V. Paiva, J. R. Ayres, \& C. M. Buchalla (Orgs.), Vulnerabilidade e Direitos Humanos. Prevenção e Promoção da Saúde: Vol. 1. Da doença à cidadania (pp. 23-42). Curitiba, PR: Juruá.

Paiva, V., Aranha, F., Bastos, F. I. P. M., \& Grupo de Estudos em População, Sexualidade e Aids. (2008). Opiniões e atitudes em relação à sexualidade: Pesquisa nacional brasileira. Revista de Saúde Pública, 42, 54-64.

Paiva, V., Garcia, J., Santos, A. De O., Terto, V., Jr., \& Munoz-Laboy, M. (2010). Religious communities and HIV prevention: An intervention-study using human rights based approach. Global Public Health, 5, 280-294.

Paiva, V., \& Zucchi, E. (2012). Estigma, discriminação e saúde: Aprendizado de conceitos e práticas no contexto da epidemia de HIV/Aids. In V. Paiva, J. R. Ayres, \& C. M. Buchalla (Orgs.), Vulnerabilidade e Direitos Humanos. Prevenção e Promoção da Saúde: Vol. 1. Da doença a cidadania (pp. 111-144). Curitiba, PR: Juruá.

Parker, R., \& Aggleton, P. (2001). Estigma, discriminação e AIDS: Vol. 1. Coleção Cidadania e direitos. Rio de Janeiro, RJ: Associação Brasileira Interdisciplinar de AIDS

Parker, R., \& Aggleton, P. (2003). HIV and AIDS related stigma and discrimination: A conceptual framework and implications for action. Social Science \& Medicine, 57, 13-24.

Parker, R., Garcia, J., \& Muñoz-Laboy, M. (2013). Sexual Social Movements and Communities. In D. L. Tolman \& L. Diamond (Eds.), The American Psychological Association's Handbook of Sexuality and Psychology. Washington, DC: American Psychological Association.

Perea, J. G. F. (2004). Tres reflexiones sobre la sexualidad y los derechos humanos en el ámbito de la Iglesia católica. Estudios Demográficos y Urbanos, 57, 639-686.

Peres, J. F. P., Simão, M. J. P., \& Noasello, A. G. (2007). Espiritualidade, religiosidade e psicote- rapia. Revista de Psiquiatria Clínica, 34(Suppl. 1), 136-145. Recuperado em 27 de março de 2012, de SciELO.

Perucchi, J., Rodrigues, F. D., Jardim, L. N., \& Calais, L. B. (2011). Psicologia e Políticas Públicas em HIV/AIDS: Algumas reflexões. Psicologia \& Sociedade, 23, 72-80.

Pollozi, L., \& Souza, C. A. M. (Orgs.). (2001). Franco Montoro, humanismo e política. São Paulo, SP: Edições Loyola.

Religioso diz que CNBB só condena preservativo por pressão da Santa Sé. (2000, 26 jun.). Folha de São Paulo.

Sampaio, J., \& Araújo, J. L., Jr. (2006). A relevância dos aspectos sócio-culturais para as políticas públicas de prevenção em AIDS. Psicologia Política, 6(11), 83-106.

Sanchez, Z. V. D. M., \& Nappo, S. A. (2008). Religious treatments for drug addiction: An exploratory study in Brazil. Social Science \& Medicine, 67, 638-646.

Seffner, F., Garcia, J., Muñoz-Laboy, M., \& Parker, R. (2011). A time for dogma, a time for the Bible, a time for condoms: Building a Catholic theology of prevention in the face of public health policies at Casa Fonte Colombo in Porto Alegre, Brazil. Global public health, 6(sup2), S271-S283.

Seffner, F., Gonçalves, C. M., Maksud, I., Garcia, J., Rios, L. F, Natividade, M., ...Parker, R. (2008). Respostas religiosas à Aids no Brasil: Impressões de pesquisa acerca da pastoral de DST/Aids da igreja católica. Ciencias Sociais e Religião, 10(10), 159.

Silva, C. G., Santos, A. O., Carli, D., \& Paiva, V. (2008, out./dez.). Religiosidade, juventude e sexualidade: Entre a autonomia e a rigidez. Psicologia em Estudo, 13(4), 683-692

Souza, P. O., Santos, N., Almeida, V., \& Paiva, V. (2012). O trabalho colaborativo com comunidades religiosas para a prevenção do HIV/Aids: A experiência do GT-Religiões em São Paulo. In V. Paiva, J. R. Ayres, \& C. M. Buchalla (Orgs.), Vulnerabilidade e Direitos Humanos: Vol. 1. Prevenção e Promoção da Saúde (pp. 239-271). Curitiba, PR: Juruá.

Teixeira, P. R. (1997). Políticas públicas em AIDS. In R. Parker, Políticas, instituições e AIDS: Enfrentando a epidemia no Brasil. Rio de janeiro, RJ: Associação Brasileira Interdisciplinar de AIDS. 
Teixeira, P. R. (2003). Universal access to AIDS medicines: The Brazilian experience. Divulgação em Saúde para Debate, 27, 184-191.

Transferetti, J. (2001). Pastoral da Família e AIDS: Comunicação, saúde e conscientização. São Paulo, SP: Átomo.

Transferetti, J. (2005). CNBB, AIDS e Governo: Tarefas para uma teologia da prevenção. Campinas, SP: Átomo.

Vasconcellos, E. G. (1992). Aids e a morte psicossomática. In V. S. F. Paiva \& L. B. N. Alonso Fernandes (Orgs.), Em tempos da AIDS (pp. 32-37). São Paulo, SP: Summus.
Watanabe, T. H. B. (2005). Caminhos e histórias: A historiografia do protestantismo na Igreja Presbiteriana do Brasil. Revista de Estudos da Religião, 1, 15-30.

Zurba, M. C. (2011). Contribuições da Psicologia Social para o psicólogo na saúde coletiva. Psicologia \& Sociedade, 23, 5-11.

Recebido: 19/07/2012

Aceite final: 29/08/2012 